\title{
Genetic diversity of Burkholderia (Proteobacteria) species from the Caatinga and Atlantic rainforest biomes in Bahia, Brazil
}

\author{
A.C. Santini, H.R.M. Santos, E. Gross and R.X. Corrêa \\ Centro de Biotecnologia e Genética, Departamento de Ciências Biológicas, \\ Universidade Estadual de Santa Cruz, Ilhéus, BA, Brasil \\ Corresponding author: R.X. Corrêa \\ E-mail: ronanxc@uesc.br
}

Genet. Mol. Res. 12 (1): 655-664 (2013)

Received March 5, 2012

Accepted August 6, 2012

Published March 11, 2013

DOI http://dx.doi.org/10.4238/2013.March.11.13

\begin{abstract}
The genus Burkholderia ( $\beta$-Proteobacteria) currently comprises more than 60 species, including parasites, symbionts and free-living organisms. Several new species of Burkholderia have recently been described showing a great diversity of phenotypes. We examined the diversity of Burkholderia spp in environmental samples collected from Caatinga and Atlantic rainforest biomes of Bahia, Brazil. Legume nodules were collected from five locations, and $16 \mathrm{~S}$ rDNA and recA genes of the isolated microorganisms were analyzed. Thirty-three contigs of $16 \mathrm{~S}$ rRNA genes and four contigs of the recA gene related to the genus Burkholderia were obtained. The genetic dissimilarity of the strains ranged from 0 to $2.5 \%$ based on $16 \mathrm{~S}$ rDNA analysis, indicating two main branches: one distinct branch of the dendrogram for the B. cepacia complex and another
\end{abstract}


branch that rendered three major groups, partially reflecting host plants and locations. A dendrogram designed with sequences of this research and those designed with sequences of Burkholderia-type strains and the first hit BLAST had similar topologies. A dendrogram similar to that constructed by analysis of $16 \mathrm{~S}$ rDNA was obtained using sequences of the fragment of the rec A gene. The 16S rDNA sequences enabled sufficient identification of relevant similarities and groupings amongst isolates and the sequences that we obtained. Only 6 of the 33 isolates analyzed via 16S rDNA sequencing showed high similarity with the B. cepacia complex. Thus, over $3 / 4$ of the isolates have potential for biotechnological applications.

Key words: $16 \mathrm{~S}$ rDNA; recA; Inga; Calliandra; Mimosa; Legume nodule

\section{INTRODUCTION}

The genus Burkholderia currently comprises more than 60 species, most of them recently described (Suarez-Moreno et al., 2012). They are widely distributed in nature and found in soil, water, rhizosphere and in association with plants. They are also found in clinical samples, infecting patients with cystic fibrosis (Zhang and Xie, 2007; Garau et al., 2009; Marquez-Santacruz et al., 2010; Wong-Villarreal and Caballero-Mellado, 2010) .

Besides habitat diversity, Burkholderia species exhibit high genetic and phenotypic diversity, which means that two strains may have very similar $16 \mathrm{~S}$ rDNA and the rest of the genome may be so different, that it would not allow classification within the same species. The high versatility and plasticity of this genus are due to the presence of replicons in its genetic material, in addition to genome size, ranging from about 5 to 9 megabases (Coenye and Vandamme, 2003; Payne et al., 2005; Zhang and Xie, 2007; Garau et al., 2009).

Thus, 16S rDNA gene sequencing, which has traditionally been used in phylogenetic studies, is often not sufficient to allocate isolates of Burkholderia at the species level. The sequencing of housekeeping genes such as recA allows molecular identification of strains with higher resolution (Payne et al., 2005; Procopio et al., 2009).

Several Burkholderia species are involved in agronomical and biotechnological applications, such as: i) production of antifungal substances for medical, veterinary and agricultural purposes (Sultan et al., 2008); ii) biodegradation of polluting compounds such as trichloroethene (Zhang et al., 2000); iii) ability to fix nitrogen (Wong-Villarreal and Caballero-Mellado, 2010); iv) phosphate-solubilization (Valverde et al., 2006), or v) production of phytohormones (Shaharoona et al., 2007) promoting plant growth, and direct antagonism or induction of resistance against pathogens (Vandamme et al., 2007). Thus, the study of this genus is relevant for bioprospecting of new species or even strains with new or more pronounced properties with potential application in biotechnology (Chiarini et al., 2004; Kang et al., 2004; Li et al., 2007; O'Sullivan and Mahenthiralingam, 2005; Payne et al., 2005).

It is widely recognized that comparative genetic analysis between novel and previously characterized strains or species may show similarities in phenotypes of interest 
(Garau et al., 2009; Wong-Villarreal and Caballero-Mellado, 2010). Therefore, considering the number of species of Burkholderia that have recently been described (SuarezMoreno et al., 2012), the agronomic and biotechnological importance of this microbial genus (Compant et al., 2008), and also the agronomic relevance and environmental conservation in Bahia, Brazil, were motives to carry out this research. The main objectives of this study were: i) to collect and isolate new strains of the genus Burkholderia from root nodules of legumes in different regions from Caatinga and Mata Atlantica in Bahia, Brazil, ii) to characterize them genetically by $16 \mathrm{~S}$ rRNA and recA gene sequencing, and iii) to characterize the diversity between two main biomes and host plants.

\section{MATERIAL AND METHODS}

\section{Microorganism isolation}

Root nodules were obtained from the following host legume plants: Inga vera Willd, Mimosa ophthalmocentra Benth, Mimosa xanthocentra Mart, Calliandra germana Barneby, Calliandra luetzelburgii Harms, and Calliandra hirtiflora Benth, all belonging to the subfamily Mimosoideae. Samples were collected from two different environmental biomes, Caatinga (Raso da Catarina, Serra do Tromba, Pico do Barbado, and Piatã) and Mata Atlantica (Serra Bonita), both located in the State of Bahia. GPS locations are listed in Table 1. Once collected, the nodules were washed with $90 \%$ alcohol for $30 \mathrm{~s}$, followed by $1 \%$ aqueous hypochlorite for $2 \mathrm{~min}$, and then washed five times with distilled sterile water. Nodules were aseptically cut transversely, collected with tweezers and plated in SDM-79 medium (Fred and Waksman, 1928). Plates were incubated at $28^{\circ} \mathrm{C}$ for 5 days.

\section{DNA isolation and PCR amplification of rDNA and recA}

Isolated colonies were transferred to $1.5-\mathrm{mL}$ microcentrifuge tubes containing 1 $\mathrm{mL}$ TY liquid medium, and incubated at $28^{\circ} \mathrm{C}$ for $72 \mathrm{~h}$, in a rotary shaker at $130 \mathrm{rpm}$. DNA was extracted according to Edwards et al. (1991) with modifications in the extraction buffer (200 mM Tris- $\mathrm{HCl}, \mathrm{pH} 8.0,1.5 \mathrm{M} \mathrm{NaCl}, 250 \mathrm{mM}$ EDTA, 0.5\% SDS and $3 \mathrm{M}$ potassium acetate). DNA was purified with $24: 1$ chloroform:isoamyl alcohol, treated with $25 \%$ ammonium acetate and cold $75 \%$ isopropanol, washed with $70 \%$ ethanol and resuspended in sterile MilliQ water. 16S rDNA was amplified using universal primers F27 and R1525 (Lane, 1991), while the primers BUR3 and BUR4 (Payne et al., 2005) were used for $r e c$ A amplification.

The 16S rDNA was amplified using $30 \mathrm{mM} \mathrm{MgCl} 2,0.2 \mathrm{mM}$ dNTP, 0.2 pmol of each primer (F27 and R1525), $1 \mathrm{U}$ Taq and $1-2 \mu \mathrm{g} / \mathrm{mL}$ genomic DNA. PCRs were carried out as follows: 1 cycle of $94^{\circ} \mathrm{C}$ for $4 \mathrm{~min} ; 35$ cycles of $94^{\circ} \mathrm{C}$ for $30 \mathrm{~s}, 61^{\circ} \mathrm{C}$ for $30 \mathrm{~s}$, and $72^{\circ} \mathrm{C}$ for $1 \mathrm{~min}$ and $30 \mathrm{~s}$, and a final 10 -min extension at $72^{\circ} \mathrm{C}$.

For rec $\mathrm{A}$ gene amplification, the same reaction conditions were used as above, except for the use of primers BUR3 and BUR4 and $20 \mathrm{mM} \mathrm{MgCl}$. PCR products were visualized in a UV transilluminator after electrophoresis at $80 \mathrm{~V}$ on a $1 \%$ agarose gel stained with ethidium bromide. 


\section{DNA sequencing and molecular analysis}

The material was sequenced by Macrogen Corp. (http://www.macrogen.com; Rockville, MD, USA), and only sequences with consistent contigs were used (overlapping forward and reverse sequences). The programs MEGA (Tamura et al., 2007), ClustalW (Thompson et al., 2002), Mega BLAST (Altschul et al., 1997), and CAP3 (Huang and Madan, 1999) were used for data analysis. Dendrograms were generated by neighbor-joining method using the Jukes-Cantor algorithm. Trees were subjected to bootstrap analysis with 1000 repetitions using only the sequence contigs generated and identified by Mega BLAST as strains close to the genus Burkholderia. The 16s rRNA sequences of 46 Burkholderia-type strains previously characterized, as well as those that refer to access returning the first hits (BLASTN) compared to those isolated in this study, were imported from Ribosomal Database Project (Cole et al., 2009) and GenBank (Benson et al., 2011), respectively, and used for the alignments.

\section{RESULTS}

Among the 127 isolates from collecting expeditions, 33 isolates were genetically characterized as Burkholderia (Table 1). 16S rDNA gene amplification with universal primers F27 and R1525 generated bands of approximately 1500 bp for all strains, as expected. Using the Mega BLAST and CAP3 programs, we obtained and identified 33 contigs belonging to the genus Burkholderia: 11 from Mata Atlântica (all from I. vera) and 22 from the Caatinga (13 from C. luetzelburgii; 4 from C. germana; 3 from M. ophthalmocentra, and 2 from $M$. xanthocentra). Isolates from $C$. hirtiflora did not generate contigs and were therefore not included in the analysis.

\begin{tabular}{|c|c|c|c|c|c|}
\hline Biome & Site & Host & Altitude (m) & GPS & Isolates* \\
\hline \multirow[t]{4}{*}{ Caatinga } & Pico do Barbado & Mimosa xanthocentra & 1455 & $13^{\circ} 17^{\prime} \mathrm{S} 41^{\circ} 53^{\prime} \mathrm{W}$ & 805,807 \\
\hline & Serra do Tromba & Calliandra germana & 1495 & $13^{\circ} 16^{\prime} \mathrm{S} 41^{\circ} 47^{\prime} \mathrm{W}$ & $810,811,812,813$ \\
\hline & Piatã & $\begin{array}{l}\text { Calliandra luetzelburgii; } \\
\text { Calliandra hirtiflora }\end{array}$ & 1208 & $13^{\circ} 18^{\prime} \mathrm{S} 41^{\circ} 32^{\prime} \mathrm{W}$ & $\begin{array}{l}815,817,818,819,823, \\
824,826,829,831,832 \text {, }\end{array}$ \\
\hline & Raso da Catarina & Mimosa ophthalmocentra & 548 & $9^{\circ} 33^{\prime} \mathrm{S} 38^{\circ} 27^{\prime} \mathrm{W}$ & $\begin{array}{l}836,838,840 \\
927,929,935\end{array}$ \\
\hline Mata Atlântica & Serra Bonita & Inga vera & 832 & $15^{\circ} 23^{\prime} \mathrm{S} 39^{\circ} 33^{\prime} \mathrm{W}$ & 008, 272A, 272B, 273C, \\
\hline
\end{tabular}

*We have only considered the isolates to obtain a contig of forward and reverse sequences. No contig was obtained from the isolates from nodules of Calliandra hirtiflora, located in Piatã.

Similarity analysis among collected isolates led to the identification of two major branches, based on the highest level of dissimilarity: one large branch composed of groups A, $\mathrm{B}$ and $\mathrm{C}$, and a second large branch composed of group D (Figure 1). Dissimilarity between all isolates ranged from zero to $2.5 \%$. 


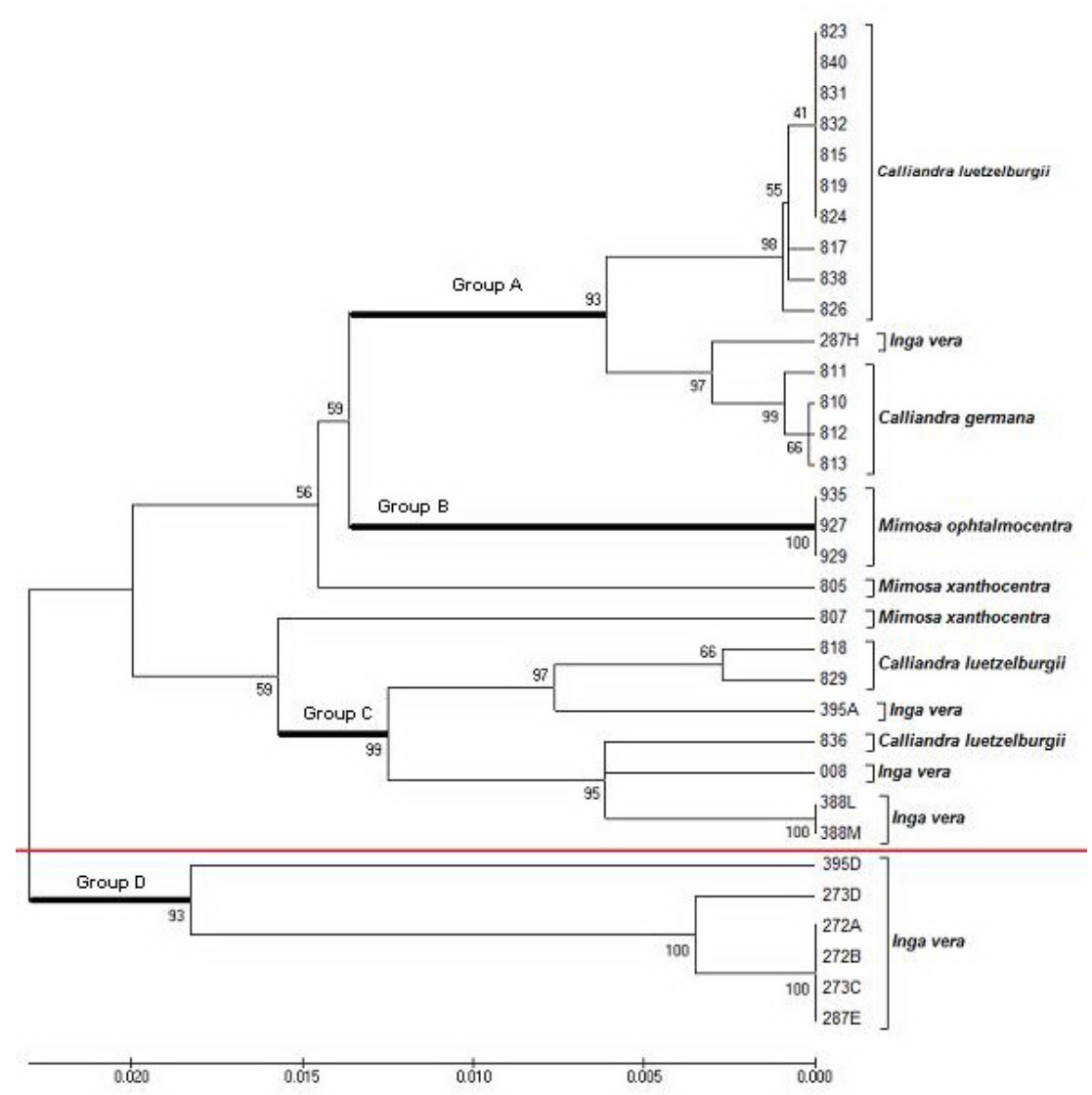

Figure 1. Bootstrap consensus tree (1000X) of the isolates obtained from nodules of legumes from five sites of Bahia and constructed from the neighbor-joining method with the Jukes-Cantor algorithm. The red line shows the division into two main branches, while the branches in bold show the formation of groups A, B, C, and D.

Group A was formed by 15 isolates, with three subgroups, each subgroup reflecting one different host plant (I. vera, C. germana and C. luetzelburgii), with bootstrap values above 93. Three isolates from $M$. ophthalmocentra formed a separate group, with $100 \%$ similarity and bootstrap of 100 (group B) and were distinguished from others with dissimilarities above $1.4 \%$. Group C, formed by 7 isolates, could be subdivided into two subgroups composed of strains from C. luetzelburgii and I. vera. Group C also reflected the relationship of the similarity of the isolates with the host plant or the biome (Figure 1). Group D was composed of only isolates of $I$. vera. Strains 272A, 272B, 273C, and 287E were 100\% similar (bootstrap 100).

The first BLAST hit of similarity yielded 2/3 of non-identified Burkholderia species (data not shown). Due to difficulties in visualizing the isolates using only the 16S rDNA sequence BLAST as a tool, a genetic distance tree was built from the 33 Burkholderia sequences obtained in this study, in addition to the sequences of the first BLAST hit and also the sequences of the Burkholderia-type strain species deposited in the Ribosomal Database Project (Figure 2). 


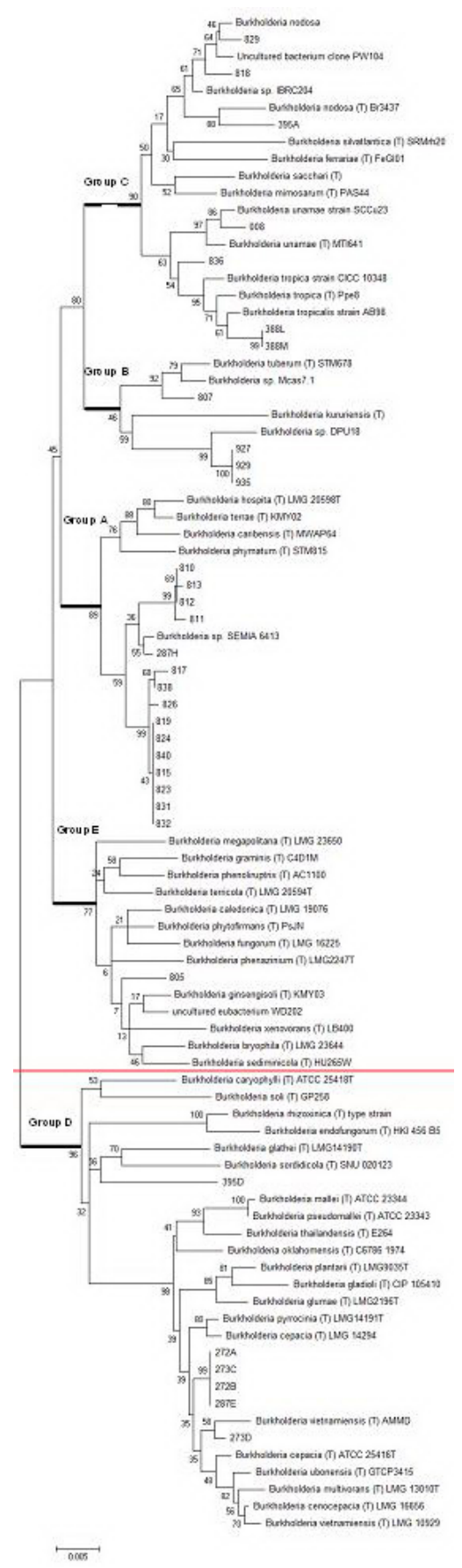

Figure 2. Bootstrap consensus tree $(1000 \mathrm{X})$ of the isolate sequences, the strains available in the database and the first BLAST hits constructed from the neighbor-joining method with the Jukes-Cantor algorithm. The red line shows the division into two main branches, while the branches in bold show the formation of groups A, B, C, D, and E. 
The tree built with the addition of the database sequences and first BLAST hit (Figure 2) had the same topology as the tree built with only the strains obtained in this study (Figure 1). Isolate 805 , from M. xanthocentra, separated from the other isolates in the first dendrogram (Figure 1) and formed a new group E (Figure 2). Isolate 807, from M. xanthocentra, also separated from the groups in the first dendrogram (Figure 1) and grouped in this second analysis with the isolates of $M$. ophthalmocentra (group B). Genetic distances varied slightly between groups when comparing the two different dendrograms, but a maximum dissimilarity of $2.5 \%$ between the two main branches was maintained.

The recA gene amplification with primers BUR3 and BUR4 generated weak bands of expected size (380 bp). The PCR for those primers could not be optimized to yield goodquality products, not permitting reliable sequencing results. Therefore, only four contigs were obtained (272A, 272B, 395A, and 395D). They were used to construct a tree, and the results were consistent with the ones shown in Figures 1 and 2, with dissimilarity values ranging between 0.75 and $6 \%$ (data not shown).

\section{DISCUSSION}

The newly obtained $16 \mathrm{~S}$ rDNA sequences, although they are very similar among themselves, allowed the differentiation of the 4 groups (Figure 1). The use of sequences of strains for the generation of a dendrogram, including the isolates under study, allowed a better comparative characterization when compared with the BLAST tool.

The analysis involving multiple alignments of sequences and clusters has been successfully applied to characterize the diversity of Burkholderia spp, as it allows the formation of distinct groups that tend to reflect their phenotypical characteristics (Garau et al., 2009; Wong-Villarreal and Caballero-Mellado, 2010). Direct comparison of the isolates (Figure 1) suggested that despite a low overall dissimilarity (given by the scale of the dendrogram branch), 16S rDNA sequencing was sufficient to allow the formation of groups. Both approaches of dendrogram generation yielded similar topology (Figures 1 and 2).

The 16s rDNA sequence analysis was sufficient to identify relevant similarities and groupings between isolates of this study and the strains of the genus. In some cases (e.g., isolates $836,388 \mathrm{~L}$ and 395D), strains separated from groups, suggesting the possibility of dealing with new species of Burkholderia awaiting more detailed taxonomic description.

In group $\mathrm{A}$, in which most of the isolates of $C$. luetzelburgii were grouped, there are soil species, some of them nodulant and diazotrophic, such as B. phymatum (Gyaneshwar et al., 2011), and others producing gluconic acid and exopolysaccharides, such as $B$. caribensis (Achouak et al., 1999). Likewise, all isolates obtained from M. ophthalmocentra plus the isolate of $C$. luetzelburgii were grouped with nitrogen-fixing species (group B), nodulating B. tuberum (Vandamme et al., 2002) and B. kururiensis capable of degrading trichloroethylene (Zhang et al., 2000). Group $C$ was also non-homogeneous concerning biotechnological properties of interest (Figure 1), as we could observe in a) the presence of nitrogen-fixing species (B. mimosarum, B. nodosa, B. unamae and B. tropica) (WongVillarreal and Caballero-Mellado, 2010), b) phosphate solubilizers (B. ferriae) (Valverde et al., 2006), c) producers of biodegradable polymers such as polyhydroxyalcanoate (PHA) from sucrose (B. sacchari) (Bramer et al., 2001), and d) even species with activity against fungi and nematodes (B. tropicalis) (Mehnaz, 2011). 
Group E comprised environmental dye-producing species of industrial and pharmaceutical interest such as phenazine (B. phenazinium) (Viallard et al., 1998) and antifungal substances (B. bryophila and B. megapolitana) (Vandamme et al., 2007). Species involved in bioremediation (B. phenoliruptrix and B. xenovorans) (Coenye et al., 2004) and present in the rhizosphere with beneficial association with plants (B. graminis and $B$. caledonia) (Viallard et al., 1998) are also part of this group. It is worth mentioning, however, that this group also includes a fungal endosymbiont (B. fungorum), which although present in the environment is also an opportunistic microbe. This species represents an exception among the isolates of Burkholderia that do not belong to the BCC (Coenye et al., 2002). Thus, the commercial use of species closely related to B. fungorum should be carefully studied.

Group D was the most genetically distant from others, and is composed of pathogens for humans and animals (BCC, B. mallei and B. pseudomallei) (Dalmastri et al., 2003; Compant et al., 2008) and for plants (B. plantarii, B. glumae and B. gladioli) (Maeda et al., 2006). Only a few free-living soil species are present in this group: one capable of plant growth promotion (B. caryophylli) (Shaharoona et al., 2007), and two others (B. rhizoxinica and B. fungorum) are endosymbionts of pathogenic fungi (Partida-Martinez et al., 2007). According to these results, 6 of the 11 isolates of I. vera from the Mata Atlântica biome are mainly interesting for research related to pathogenicity (Figure 2).

Of the 33 isolates analyzed in this study, only one is relatively close to B. fungorum, and six showed high similarity with BCC. Thus, over $78 \%$ of the isolates showed a perspective of studies for future biotechnological applications in different areas of interest.

There was congruence of the dendrograms obtained from 16S rDNA and rec A gene sequencing data, in a subset of isolates. Therefore, the data obtained in this study from the recA gene sequences are consistent with the literature (Payne, et al., 2005). In-depth studies of species present in Mata Atlântica and Caatinga are necessary to overcome the observed difficulties in the recA gene amplification.

\section{CONCLUSIONS}

Sequencing of 16s rRNA was sufficient to identify relevant similarities and groupings among isolates and the sequences deposited. We could not optimize PCR for BUR3 and BUR4 primers for the strains in this study, but the few sequences of the partial recA gene obtained generated a dendrogram congruent with the $16 \mathrm{~S}$ rDNA tree. Dendrogram groupings partially reflect biomes or host plants. This study showed that $78 \%$ of the 33 isolates studied have a good potential for future studies regarding biotechnological applications.

\section{ACKNOWLEDGMENTS}

Research supported by Conselho Nacional de Desenvolvimento Científico (CNPq) (\#620147/2004-0). We thank José Miguel Ferreira dos Santos for collecting samples, Alinne Batista Ambrósio for providing isolates from Raso da Catarina, Luciano Angelo de Souza Bernardes for suggestions and Martin Brendel for English editing. A doctoral fellowship was provided by CAPES. This paper is dedicated to the memory of Julio Cézar de Mattos Cascardo, who greatly contributed to this research. 


\section{REFERENCES}

Achouak W, Christen R, Barakat M, Martel MH, et al. (1999). Burkholderia caribensis sp. nov., an exopolysaccharideproducing bacterium isolated from vertisol microaggregates in Martinique. Int. J. Syst. Bacteriol. 49 Pt 2: 787-794.

Altschul SF, Madden TL, Schaffer AA, Zhang J, et al. (1997). Gapped BLAST and PSI-BLAST: a new generation of protein database search programs. Nucleic Acids Res. 25: 3389-3402.

Benson DA, Karsch-Mizrachi I, Lipman DJ, Ostell J, et al. (2011). GenBank. Nucleic Acids Res. 39: D32-D37.

Bramer CO, Vandamme P, da Silva LF, Gomez JG, et al. (2001). Polyhydroxyalkanoate-accumulating bacterium isolated from soil of a sugar-cane plantation in Brazil. Int. J. Syst. Evol. Microbiol. 51: 1709-1713.

Chiarini L, Cescutti P, Drigo L, Impallomeni G, et al. (2004). Exopolysaccharides produced by Burkholderia cenocepacia recA lineages IIIA and IIIB. J. Cyst. Fibros. 3: 165-172.

Coenye T and Vandamme P (2003). Diversity and significance of Burkholderia species occupying diverse ecological niches. Environ. Microbiol. 5: 719-729.

Coenye T, Goris J, Spilker T, Vandamme P, et al. (2002). Characterization of unusual bacteria isolated from respiratory secretions of cystic fibrosis patients and description of Inquilinus limosus gen. nov., sp. nov. J. Clin. Microbiol. 40: 2062-9.

Coenye T, Henry D, Speert DP and Vandamme P (2004). Burkholderia phenoliruptrix sp. nov., to accommodate the 2,4,5-trichlorophenoxyacetic acid and halophenol-degrading strain AC1100. Syst. Appl. Microbiol. 27: 623-627.

Cole JR, Wang Q, Cardenas E, Fish J, et al. (2009). The Ribosomal Database Project: improved alignments and new tools for rRNA analysis. Nucleic Acids Res. 37: D141-D145.

Compant S, Nowak J, Coenye T, Clement C, et al. (2008). Diversity and occurrence of Burkholderia spp. in the natural environment. FEMS Microbiol. Rev. 32: 607-626.

Dalmastri C, Fiore A, Alisi C, Bevivino A, et al. (2003). A rhizospheric Burkholderia cepacia complex population: genotypic and phenotypic diversity of Burkholderia cenocepacia and Burkholderia ambifaria. FEMS Microbiol. Ecol. 46: 179-187.

Edwards K, Johnstone C and Thompson C (1991). A simple and rapid method for the preparation of plant genomic DNA for PCR analysis. Nucleic Acids Res. 19: 1349.

Fred EB and Waksman SA (1928). Laboratory Manual of General Microbiology - With Special Reference to the Microorganisms of the Soil. McGraw-Hill Book Company, New York.

Garau G, Yates RJ, Deiana P and Howieson JG (2009). Novel strains of nodulating Burkholderia have a role in nitrogen fixation with papilionoid herbaceous legumes adapted to acid, infertile soils. Soil Biol. Biochem. 41: 125-134.

Gyaneshwar P, Hirsch AM, Moulin L, Chen WM, et al. (2011). Legume-nodulating betaproteobacteria: diversity, host range, and future prospects. Mol. Plant Microbe Interact. 24: 1276-1288.

Huang X and Madan A (1999). CAP3: A DNA sequence assembly program. Genome Res. 9: 868-877.

Kang JG, Shin SY, Kim MJ, Bajpai V, et al. (2004). Isolation and anti-fungal activities of 2-hydroxymethyl-chroman-4one Produced by Burkholderia sp. MSSP. J. Antibiot. 57: 726-731.

Lane DJ (1991). 16S/23S rRNA Sequencing. In: Nucleic acid Thecniques in Bacterial Systematics (Stackebrandt E and Goodfellow M, eds.). Wiley, New York, 115-175.

Li X, Quan CS and Fan SD (2007). Antifungal activity of a novel compound from Burkholderia cepacia against plant pathogenic fungi. Lett. Appl. Microbiol. 45: 508-514.

Maeda Y, Shinohara H, Kiba A, Ohnishi K, et al. (2006). Phylogenetic study and multiplex PCR-based detection of Burkholderia plantarii, Burkholderia glumae and Burkholderia gladioli using gyrB and rpoD sequences. Int. J. Syst. Evol. Microbiol. 56: 1031-1038.

Marquez-Santacruz HA, Hernandez-Leon R, Orozco-Mosqueda MC, Velazquez-Sepulveda I, et al. (2010). Diversity of bacterial endophytes in roots of Mexican husk tomato plants (Physalis ixocarpa) and their detection in the rhizosphere. Genet. Mol. Res. 9: 2372-2380.

Mehnaz S (2011). Plant Growth-Promoting Bacteria Associated with Sugarcane. In: Bacteria in Agrobiology: Crop Ecosystems (Maheshwari DK, ed.). Springer, Berlin, 165-187.

O'Sullivan LA and Mahenthiralingam E (2005). Biotechnological potential within the genus Burkholderia. Lett. Appl. Microbiol. 41: 8-11.

Partida-Martinez LP, Groth I, Schmitt I, Richter W, et al. (2007). Burkholderia rhizoxinica sp. nov. and Burkholderia endofungorum sp. nov., bacterial endosymbionts of the plant-pathogenic fungus Rhizopus microsporus. Int. J. Syst. Evol. Microbiol. 57: 2583-2590.

Payne GW, Vandamme P, Morgan SH, Lipuma JJ, et al. (2005). Development of a recA gene-based identification approach for the entire Burkholderia genus. Appl. Environ. Microbiol. 71: 3917-3927. 
Procopio RE, Araujo WL, Maccheroni W, Jr. and Azevedo JL (2009). Characterization of an endophytic bacterial community associated with Eucalyptus spp. Genet. Mol. Res. 8: 1408-1422.

Shaharoona B, Jamro GM, Zahir ZA, Arshad M, et al. (2007). Effectiveness of various Pseudomonas spp. and Burkholderia caryophylli containing ACC-deaminase for improving growth and yield of wheat (Triticum aestivum L.). J. Microbiol. Biotechnol. 17: 1300-1307.

Suarez-Moreno ZR, Caballero-Mellado J, Coutinho BG, Mendonca-Previato L, et al. (2012). Common features of environmental and potentially beneficial plant-associated Burkholderia. Microb. Ecol. 63: 249-266.

Sultan Z, Park K, Lee SY, Park JK, et al. (2008). Novel oxidized derivatives of antifungal pyrrolnitrin from the bacterium Burkholderia cepacia K87. J. Antibiot. 61: 420-425.

Tamura K, Dudley J, Nei M and Kumar S (2007). MEGA4: Molecular Evolutionary Genetics Analysis (MEGA) software version 4.0. Mol. Biol. Evol. 24: 1596-1599.

Thompson JD, Gibson TJ and Higgins DG (2002). Multiple sequence alignment using ClustalW and ClustalX. Curr. Protoc. Bioinformatics Chapter 2: Unit.

Valverde A, Delvasto P, Peix A, Velazquez E, et al. (2006). Burkholderia ferrariae sp. nov., isolated from an iron ore in Brazil. Int. J. Syst. Evol. Microbiol. 56: 2421-2425.

Vandamme P, Goris J, Chen WM, De Vos P, et al. (2002). Burkholderia tuberum sp. nov. \& Burkholderia phymatum sp. nov., nodulate the roots of tropical legumes. Syst. Appl. Microbiol. 25: 507-512.

Vandamme P, Opelt K, Knochel N, Berg C, et al. (2007). Burkholderia bryophila sp. nov. and Burkholderia megapolitana sp. nov., moss-associated species with antifungal and plant-growth-promoting properties. Int. J. Syst. Evol. Microbiol. 57: 2228-2235.

Viallard V, Poirier I, Cournoyer B, Haurat J, et al. (1998). Burkholderia graminis sp. nov., a rhizospheric Burkholderia species, and reassessment of [Pseudomonas] phenazinium, [Pseudomonas] pyrrocinia and [Pseudomonas] glathei as Burkholderia. Int. J. Syst. Bacteriol. 48 Pt 2: 549-563.

Wong-Villarreal A and Caballero-Mellado J (2010). Rapid identification of nitrogen-fixing and legume-nodulating Burkholderia species based on PCR 16S rRNA species-specific oligonucleotides. Syst. Appl. Microbiol. 33: 35-43.

Zhang H, Hanada S, Shigematsu T, Shibuya K, et al. (2000). Burkholderia kururiensis sp. nov., a trichloroethylene (TCE)degrading bacterium isolated from an aquifer polluted with TCE. Int. J. Syst. Evol. Microbiol. 50 Pt 2: 743-749.

Zhang L and Xie G (2007). Diversity and distribution of Burkholderia cepacia complex in the rhizosphere of rice and maize. FEMS Microbiol. Lett. 266: 231-235. 